\title{
Introduction of A Newly Developed Arbitrary Pressure Pulsation Generating Device for Evaluating The Characteristics of Gas Flow Meters and Sensors*
}

\author{
Tomonori KATO $^{* *}$, Takashi OWAKU**, Hirohisa SAKUMA ${ }^{* * *}$, Toshiharu \\ KAGAWA $^{* * * *}$
}

\begin{abstract}
The purpose of this study is to develop a novel and compact pneumatic pressure pulsation generator that can generate arbitrary pressure pulsations in a pipe system in order to evaluate the characteristics of flow meters and flow sensors. Gas flow meters and sensors (used in industrial processes and in homes) are exposed to unsteady pressure pulsations generated by the operation of other equipment and piping. In this paper, in order to establish a compact (laboratory-size) testing device to characterize gas flow meters and sensors (particularly around their zero point) at various pressure pulsations, a compact arbitrary pressure pulsation generator is developed and tested. First, using ordinary $15 \mathrm{~m}$ length piping and a T-tube, pressure pulsations are generated and supplied to two flow meters (a laminar flow sensor and an ultrasonic flow meter). Then, the pulsations are duplicated using the newly developed compact pressure pulsation generator and supplied to the flow meters. The experimental results indicate that the developed pulsation generator can accurately duplicate the pulsations generated by the ordinary piping. These results indicate that our system can potentially be used to reduce the cost of flow meter evaluation.
\end{abstract}

Keywords: Pneumatics, Flow Rate Measurement, Gas Flow Meter Testing Device

\section{Introduction}

Gas flow meters and flow sensors are widely used in industrial plants and even residential homes. The gas pressure in the pipe system can be affected by the condition of other connected equipment and the surrounding environment. Currently, the static characteristics of such flow meters and sensors are thoroughly evaluated according to strict international and domestic standards [ISO (International Organization for Standards) and JIS (Japanese Industrial Standards)]. However, gas flow meters and sensors used in industrial processes are exposed to unsteady pressure pulsations (which may contain several superimposed frequencies) that are generated by the operation of other equipment and piping (such as the reflection of pressure waves). In other words, flow meters and sensors may be measuring flow rates that contain unsteady pressure pulsations, and so the signal outputs may be influenced by these pressure pulsations ${ }^{1)}$. Currently, in order to assess the performance of flow meters and sensors in the presence of these pressure pulsations, it is necessary to

\footnotetext{
* Manuscript received September 4, 2012

** Fukuoka Institite of Technology

(3-30-1 Wajiro-higashi, Higashi-ku, Fukuoka, Japan)

E-mail: t-kato@fit.ac.jp

*** Tokyo Gas Co., Ltd.

(3-13-1 Minami-senjyu, Arakawa-ku, Tokyo, Japan)

**** Tokyo Institute of Technology

(R2-45, 4259 Nagatsuta-cho, Midori-ku, Yokohama, Kanagawa, Japan)
}

either place a meter (or sensor) at the location where the pulsation occurs or replicate the entire pipe system in the laboratory. Although a method of generating flow containing pressure pulsations using resonance tubes was reported in a previous study, this method has the following limitations:

- This method cannot generate pulsations with superimposed frequencies.

- The length of the tube must be adjusted when changing the frequency of the pulsation (this takes time and labour).

- The resonance tube, which must be installed in a straight line, takes up a great deal of space.

Therefore, a compact pressure pulsation generator that can generate arbitrary unsteady pulsations is needed for testing flow meters and sensors. In the present study, we propose a novel and compact pneumatic pressure pulsation generator that uses a very quick and precise pressure measurement and control technique. The proposed system is composed of a high-precision quick-response (HPQR) pneumatic pressure regulator and bent gas piping that simulates the gas piping in a typical home. Using this system, we assess the performance of a flow meter and a flow sensor, particularly around their zero point. In the experiment, first, pressure pulsations generated using ordinary $25 \mathrm{~m}$ length piping and a T-tube are supplied to the flow sensor and flow meter. Then, the pulsation is duplicated using the newly developed compact pressure pulsation generator, and the generated pulsation is supplied to the flow meters. Using the 
experimental results, the effectiveness of the proposed pressure pulsation generator is evaluated.

\section{Nomenclature}

$\begin{array}{lll}E_{i} & : & \text { control voltage of servo valve }[\mathrm{V}] \\ F & : & \text { frequency }[\mathrm{Hz}] \\ G & : & \text { mass flow rate }[\mathrm{kg} / \mathrm{s}] \\ K_{G I} & : & \text { integral gain }[\mathrm{V} / \mathrm{kg}] \\ K_{p} & : & \text { proportional gain }[(\mathrm{kg} / \mathrm{s}) / \mathrm{Pa}] \\ K_{v} & : & \text { flow rate gain of servo valve }[\mathrm{kg} /(\mathrm{s} \mathrm{V})] \\ P & : & \text { pressure }[\mathrm{Pa}] \\ Q & : & \text { flow rate }[\mathrm{L} / \mathrm{min} \mathrm{ANR}] \\ R & : & \text { gas constant }[\mathrm{J} /(\mathrm{kg} \mathrm{K})] \\ s t & : & \text { sampling time }[\mathrm{s}] \\ t & : & \text { time }[\mathrm{s}] \\ V & : & \text { volume }\left[\mathrm{m}^{3}\right] \\ \theta & : & \text { temperature }[\mathrm{K}]\end{array}$

\section{Development of Arbitrary Pressure Pulsation Generating Device}

\subsection{Outline of the Proposed Pressure Pulsation}

\section{Generating Device}

The concept of the proposed arbitrary pressure pulsation generator is shown in Fig.1. The system represents a gas supply pipe system between a gas company and a typical home. The generator consists of an air supply (a compressor), a pressure controlling device (the developed pressure regulator), the tested flow meter, pressure sensors, and bent gas piping that simulates the gas piping in a typical home. Before performing experiments on the developed pressure pulsation generator, the pressure pulsation in a real pipe system should be measured using the pressure sensor that is installed just upstream of the flow meter. Then, the developed pressure regulator, which can control the arbitrary pressure wave very quickly, duplicates the pressure pulsation. The gas piping downstream of the flow meter simulates the gas piping in a typical home. The effect of the volume and the reflection of pressure waves can be duplicated. In order to evaluate the characteristics around the zero point, the very

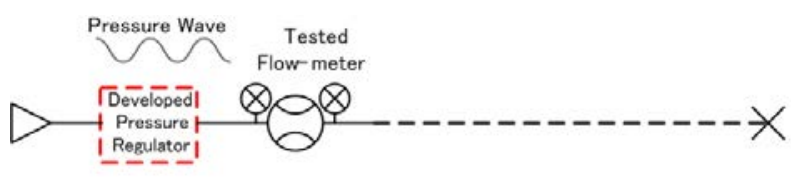

Fig.1 Concept of the Proposed Pressure Pulsation Generating Device

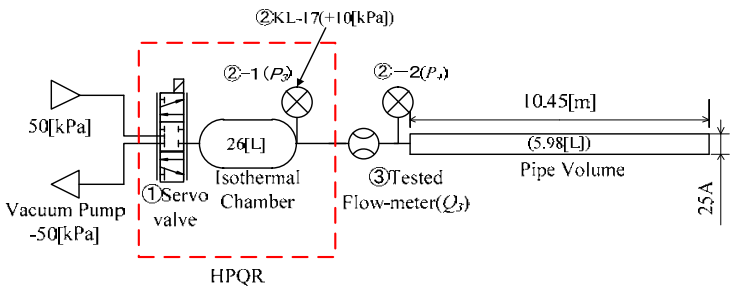

Fig.2 Schematic of the Proposed Pressure Pulsation Generating Device

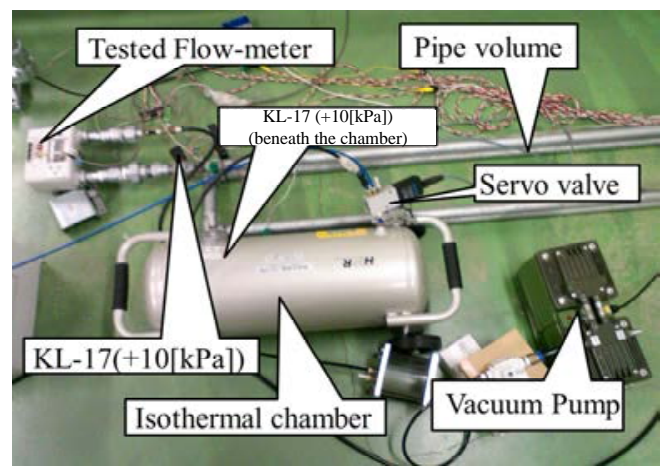

Fig.3 Picture of the Developed Pressure Regulator

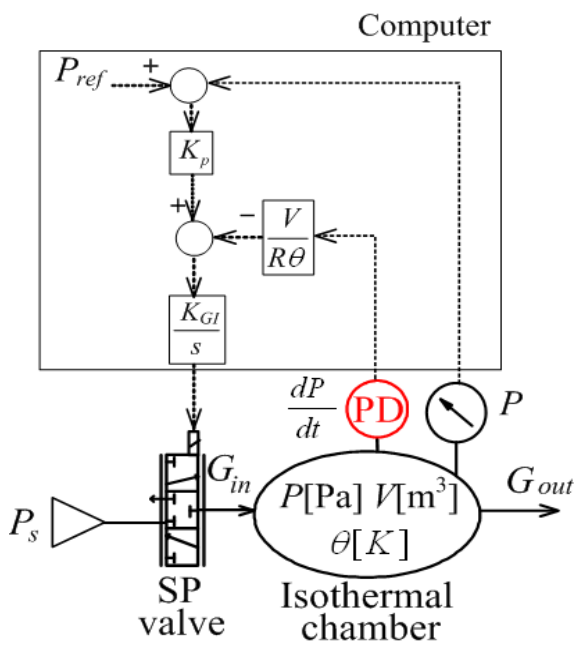

Fig.4 Schematic of the Developed Pressure Regulator

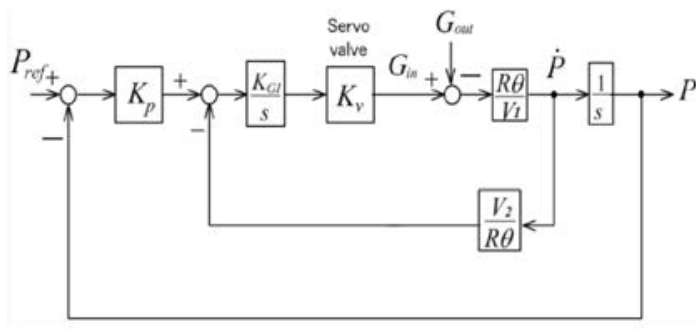

$K_{P}=3.09 \times 10^{-6}(\mathrm{~kg} / \mathrm{s}) / \mathrm{Pa}, \quad K_{G I}=3.6 \times 10^{5} \mathrm{~V} / \mathrm{kg}$

Fig.5 Block Diagram of the Developed Pressure Regulator 
end of the piping is closed. A schematic of the proposed pressure pulsation generator is shown in Fig.2.

\subsection{Pressure Pulsation Generating Device}

A picture of the developed pressure regulator is shown in Fig.3. It is composed of an SP valve (FESTO MPYE-5-M5B), an isothermal chamber, a pressure sensor (Nagano Keiki $\mathrm{KL}-17+10 \mathrm{kPa}$ ), and a vacuum pump. Although the SP valve has five ports, the valve is used as a three-port servo valve (i.e., supply, control, and exhaust ports), and the unused ports are plugged. The removal of air from the exhaust port is increased using the vacuum pump. The isothermal chamber used herein has a volume $V$ of $0.026 \mathrm{~m}^{3}$.

A schematic and a block diagram of the proposed pressure regulator are shown in Figs. 4 and 5, respectively. The SP valve characteristics are approximated to a linear constant $K_{v}$. The main loop is a pressure feedback loop. The minor loop is a differentiated value feedback loop, which compensates for the nonlinear characteristics of the SP valve and can also reduce the effects of supply pressure variation and the output flow rate $G_{\text {out }}{ }^{2}$. Since the controller gains are set as shown in Figure 5, the time constant of the pressure control loop is about $0.1 \mathrm{~s}$. The control is performed using a digital signal processor (MTT s-box) with a sampling time of $s t=0.001 \mathrm{~s}$.

\section{Experiments}

\subsection{Flow Sensor and Flow Meter}

The experiments are performed using a laminar flow sensor and an ultrasonic flow meter as the testing targets. Figure 6 and Table 1 show the laminar flow sensor and its specifications, respectively. The sensor is called a "quick response laminar flow sensor” (QFS), and our previous research confirms its dynamic response rate to be no less than $50 \mathrm{~Hz}^{3)}$. In the experiment, the signal from the QFS is measured every $0.001 \mathrm{~s}$.

Figure 7 shows an ultrasonic flow meter (USM) that is used for measuring the city gas (13A); these USMs are already used by thousands of Tokyo Gas customers. The signal from the USM is measured every $2 \mathrm{~s}$.

\subsection{Gas Pulsation Generating Experiment using an Ordinary Pipe system}

We fabricated a gas pipe system as shown in Fig.8. In the system, the air pressure is controlled using a commercially available precision pressure regulator (1) Konan RV6-03G3267). The volume of the buffer tank (2) is 30L. The pipe labeled $(40 \mathrm{~A}, 15 \mathrm{~m})$ is assumed to be an underground gas main from the gas company. The pipe labeled $(25 \mathrm{~A}, 10 \mathrm{~m})$ is installed downstream of the tested

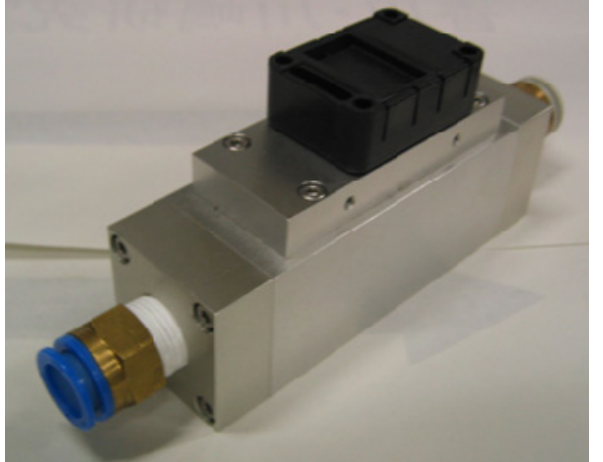

Fig.6 Picture of Quick Response Laminar Flow Sensor (QFS)

Table 1 Specifications of QFS

\begin{tabular}{|c|c|}
\hline Type & $\begin{array}{c}\text { QFS-03-50-10 (Tokyo Meter } \\
\text { Co., Ltd.) }\end{array}$ \\
\hline Inner diameter of inlet & $\mathrm{R}_{\mathrm{c}} 3 / 8$ \\
\hline Output signal range $[\mathrm{V}]$ & $0.5-4.5$ \\
\hline Dynamic response rate $[\mathrm{Hz}]$ & Not less than 50 \\
\hline Size $(\mathrm{W} \times \mathrm{H} \times \mathrm{D})[\mathrm{mm}]$ & $115 \times 70 \times 35$ \\
\hline Differential pressure sensor & Nagano-Keiki KL-17 $\pm 500 \mathrm{~Pa}$ \\
\hline
\end{tabular}

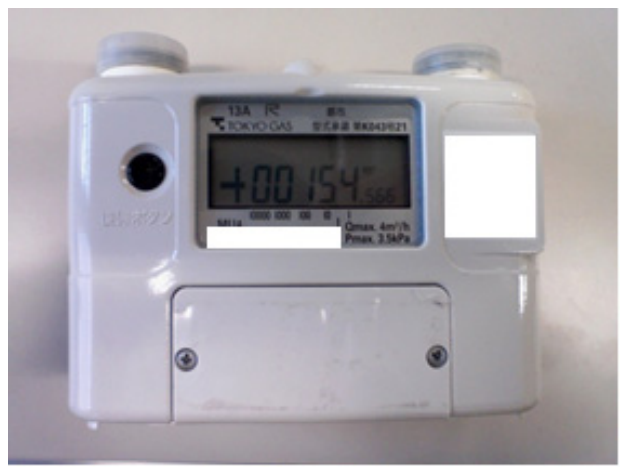

Fig.7 Picture of Ultrasonic Flow Meter (USM)

flow meter (or sensor) (7) as it would be in a typical home. The very end of the piping is closed. In the experiments, the pressure pulsation is generated using a T-tube (5) divergence pipe) and a spool-type servo valve (4) FESTO MPYE-5-1/8LF-010B). The disturbance flow rate is measured using a flow sensor (6) Tokyo Meter QFS-800). Since the end of the pipe is closed, no matter how much disturbance (pressure pulsation) is generated and supplied to the tested flow meter (or sensor), the total flow rate should be zero. The pressure values upstream and downstream of the tested flow meter (or sensor) are also measured.

\subsection{Experimental Conditions and Procedures}

In the experiment, the supply pressure is first set to about $6 \mathrm{kPa}$ (gauge) using the precision pressure regulator (1)). After the pressure sufficiently stabilizes, each experiment is started. Then, the control signal is sent to the servo valve (4) according to Equation (1). 


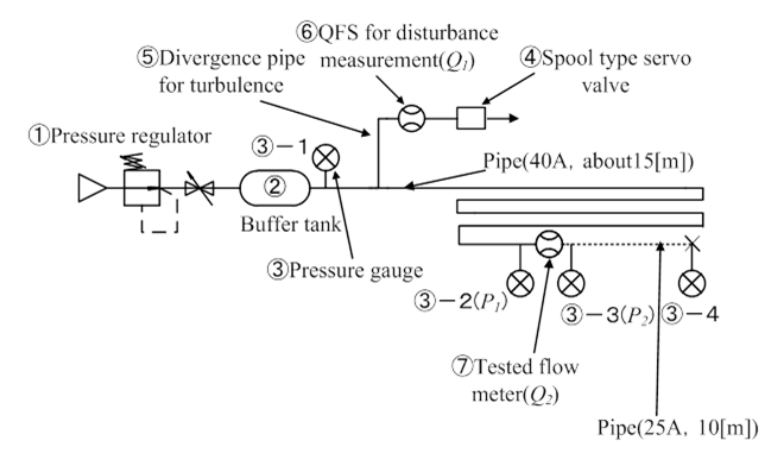

Fig.8 Schematic of Gas piping

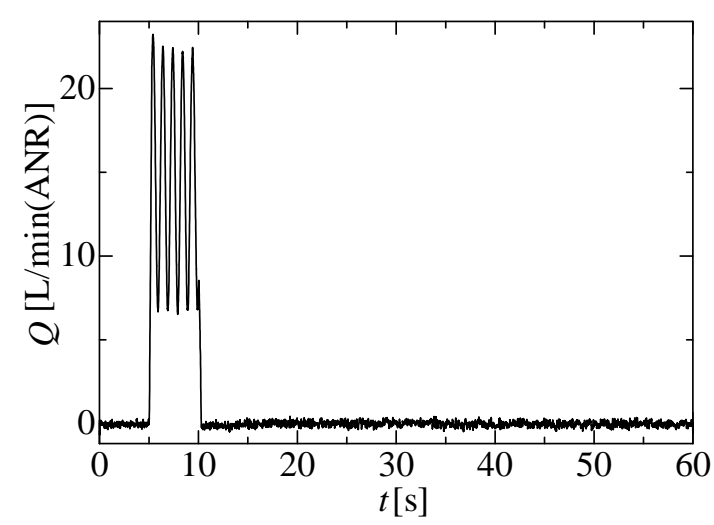

Fig.9 Measure Flow Rate (Q1)

$$
E_{i}[\mathrm{~V}]=\left\{\begin{array}{c}
0(t<5) \\
7+\sin 2 \pi f t(5 \leq t \leq 10) \\
0(10>t)
\end{array}\right.
$$

The disturbance flow rate measured by the QFS (6), $\left.Q_{1}\right)$ is shown in Fig.9. The flow rates are measured by the QFS and USM when they experience a disturbance (pressure pulsation). The pressures upstream and downstream of the flow sensor/meter are also measured using pressure sensors.

\subsection{Experimental Results}

The experimental results for the QFS are shown below.

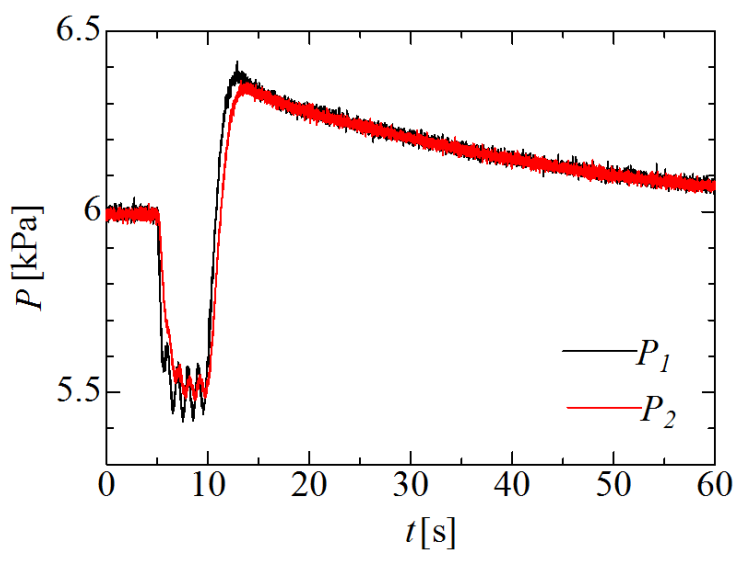

Fig.10 Measured Values of Pressure $\left(P_{1}, P_{2}\right)$ (Target: QFS)

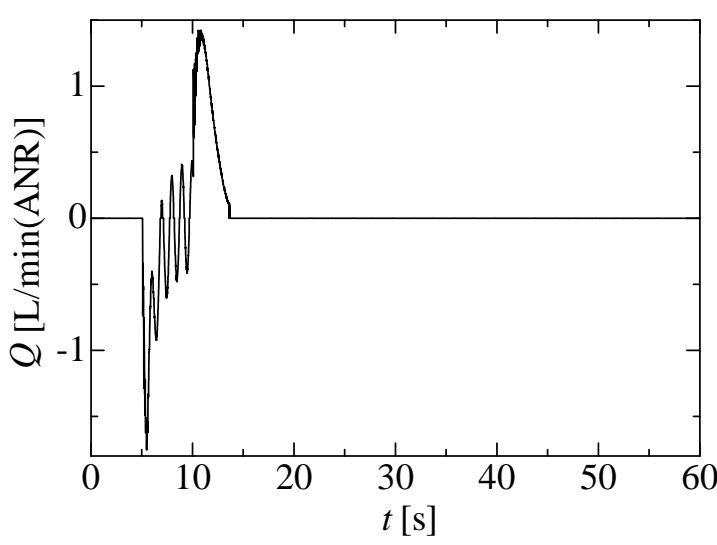

Fig.11 Measured Flow Rate $\left(Q_{2}\right)$ (Target: QFS)

The pressure values $\left(P_{1}, P_{2}\right)$ and measured flow rate from the QFS $\left(Q_{2}\right)$ are shown in Figs. 10 and 11, respectively. The difference between P1 and P2 is due to the inner impedance of the laminar flow element in the QFS. As a disturbance occurs upstream, pressure pulsations occur, and the flow rate measured by the QFS $\left(Q_{2}\right)$ also fluctuates. The measured flow rate in Fig. 11 is integrated, and the total mass of flow is calculated. The integrated value is $+0.018 \mathrm{~L}$.

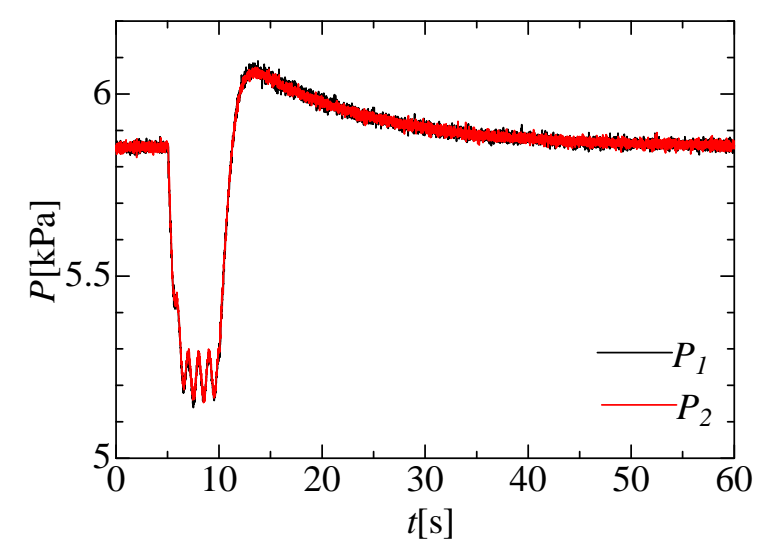

Fig.12 Measured Values of Pressure $\left(P_{1}, P_{2}\right)$ (Target: USM)

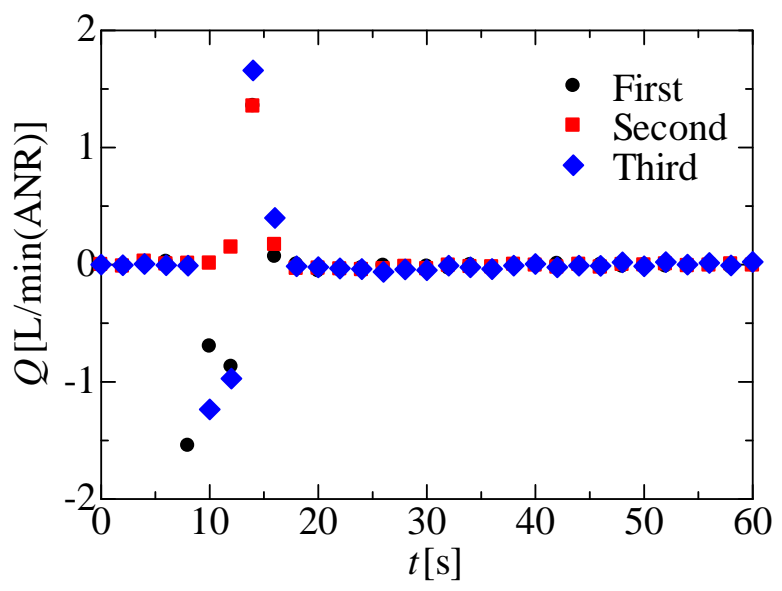

Fig.13 Measured Flow Rates (Target: USM) 
Table 2 Integrated Values of the Flow Rates

\begin{tabular}{|c|c|c|c|c|}
\hline $\begin{array}{c}\text { Type of } \\
\text { flow meter }\end{array}$ & \multicolumn{4}{|c|}{ Integrated value [L] } \\
\hline QFS & \multicolumn{4}{|c|}{+0.018} \\
\hline \multirow{2}{*}{ USM } & 1 st & 2nd & 3rd & Average \\
\cline { 2 - 5 } & -0.066 & +0.046 & -0.017 & -0.012 \\
\hline
\end{tabular}

The experimental results for the USM are shown in Fig.12 (pressure values) and Fig.13 (flow rates). Since the USM has a small inner impedance, the difference between P1 and P2 is quite small. The experiment was performed a total of three times, so there are three sets of results shown in Fig.13. The experimental result varied each time, and the average of the integrated values is $-0.012 \mathrm{~L}$ (Table 2).

\subsection{Gas Pulsation Generating Experiment using the}

\section{Developed Arbitrary Pressure Pulsation Generator}

In this section, instead of using the gas pipe system shown in Fig.8, the proposed pressure pulsation generator (Fig.2) is used. In this experiment, the measured pressure value P1 (Fig.10) is used as the set pressure value $\left(P_{\text {ref }}\right)$ of the developed pressure regulator (Fig.4). The experimental results comparing $P_{\text {ref }}$ and $P_{3}$ are shown in Fig.14; the measured pressure pulsation from the last section was duplicated very well. The measured flow rates for the QFS are shown in Fig.15 alongside the measured flow rate from the last section (Fig.11). The two flow rate curves correlate very well. The integrated value of the flow rate is $+0.018 \mathrm{~L}$, which matches the value from the experiment in the last section.

The USM experiment was performed three times, and the results are shown alongside the results from the previous section (Fig.13) in Fig.16 (there are a total of six results shown). The experimental result varied each time, and the average of the integrated values is $-0.019 \mathrm{~L}$ (Table 3).

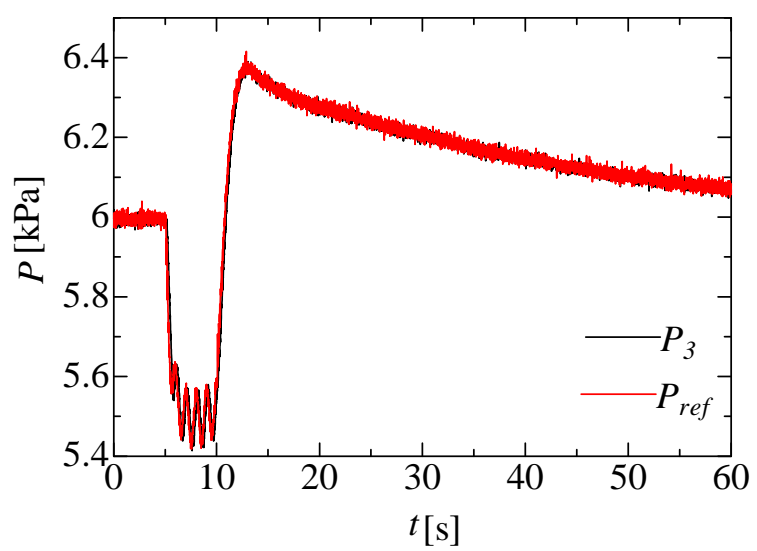

Fig.14 Comparison of Pressures $\left(P_{3}, P_{r e f}\right)$

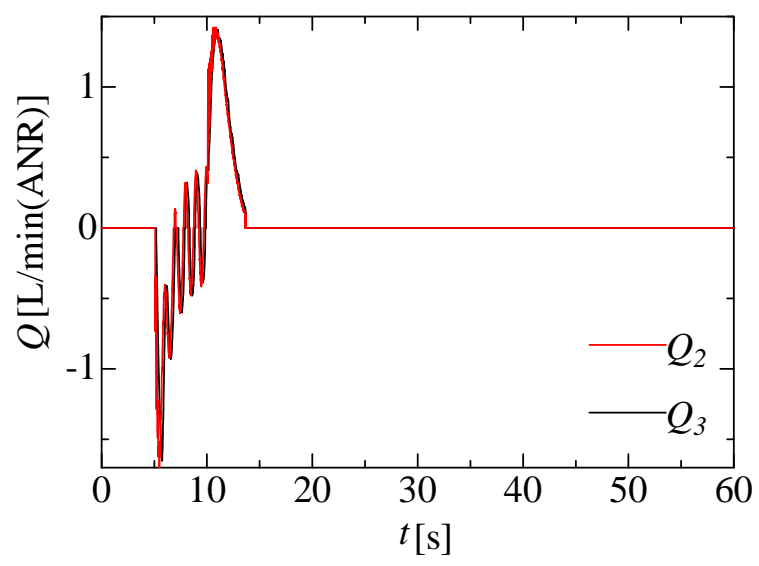

Fig.15 Comparison of Flow Rates (QFS)

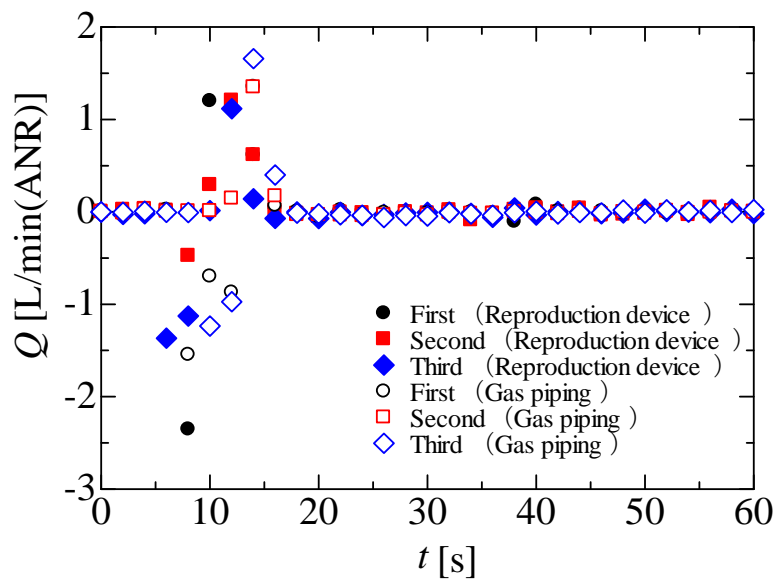

Fig.16 Comparison of Flow Rates (USM)

Table 3 Integrated Values of the Flow Rates

\begin{tabular}{|c|c|c|c|c|c|}
\hline $\begin{array}{c}\text { Type } \\
\text { of }\end{array}$ & \multicolumn{4}{|c|}{ Integrated value [L] } & $\begin{array}{l}\text { Difference } \\
\text { from }\end{array}$ \\
\hline QFS & \multicolumn{4}{|c|}{+0.018} & 0 \\
\hline \multirow[t]{2}{*}{ USM } & $1 \mathrm{st}$ & 2nd & 3rd & $\begin{array}{c}\text { Averag } \\
\text { e }\end{array}$ & \multirow[t]{2}{*}{+0.019} \\
\hline & +0.019 & +0.053 & -0.052 & +0.007 & \\
\hline
\end{tabular}

\section{Conclusions}

In order to establish a compact (laboratory-size) characteristics testing device for gas flow meters and sensors (particularly around their zero point) at various pressure pulsations, a compact arbitrary pressure pulsation generator was developed. As a preliminary experiment, before conducting the experiments using the proposed system, real pressure pulsations were generated in an upstream pipe (using $15 \mathrm{~m}$ of upstream piping and a divergence pipe) and were measured using pressure sensors and a flow meter (and a flow sensor). Then, using the proposed system, those pressure pulsations were duplicated. The experimental 
results gained by those 2 cases, were in good agreement. These experimental results indicate the effectiveness of the proposed testing method for flow meters and sensors with the presence of pressure pulsations in the piping.

This paper has been firstly presented in the 2nd JapanChina Joint Workshop on Fluid Power 2012 in Tokyo, May 23, 2012.

\section{References}

1) Gajan, P., Mottram, R.C., Herbard, P., Andriamihafy, H., Platet, B. : The influence of pulsating flows on orifice plate flowmeters, Flow Measurement Instrumentation, Vol.3, No.3, p.118-129 (1992)

2) Kawashima, K., Kato, K., Yamazaki, S., Kagawa, T. : Development of a Precise and High Response Pressure Regulator for Gases, Transactions of the Japan Fluid Power System Society, Vol.38, No.2, p.29-34 (2004)

3) Funaki, T., Sengoku, K., Kawashima, K., Kagawa, T. : Dynamic Calibration of Laminar Flow Sensor for Gases, Proc. of SICE Annual Conference 2004, CD-ROM (2004) 